\title{
Artificial night light alters nocturnal prey interception outcomes for morphologically variable spiders
}

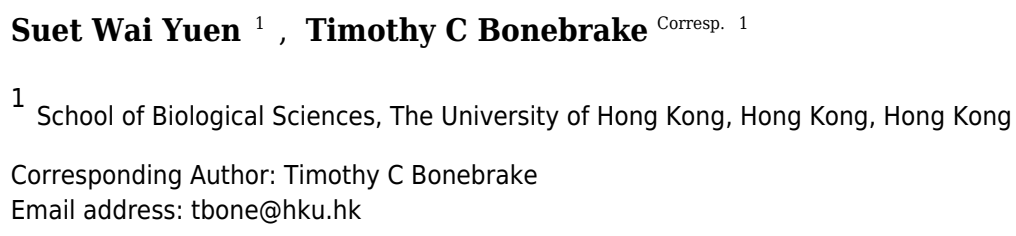

Artificial night light has the potential to significantly alter visually-dependent species interactions. However, examples of disruptions of species interactions through changes in light remain rare and how artificial night light may alter predator prey relationships are particularly understudied. In this study, we examined whether artificial night light could impact prey attraction and interception in Nephila pilipes orb weaver spiders, conspicuous predators who make use of yellow color patterns to mimic floral resources and attract prey to their webs. We measured moth prey attraction and interception responses to treatments where we experimentally manipulated the color/contrast of spider individuals in the field (removed yellow markings) and also set up light manipulations. We found that lit webs had lower rates of moth interception than unlit webs. Spider color however had no clear impact on moth interception or attraction rates in lit nor unlit webs. The results show that night light can reduce prey interception for spiders. Additionally, this study highlights how environmental and morphological variation can complicate simple predictions of ecological light pollution's disruption of species interactions. 
3 Artificial night light alters nocturnal prey interception outcomes for morphologically variable spiders

5

6

$10{ }^{1}$ The School of Biological Sciences, The University of Hong Kong, Hong Kong

16 Corresponding author

17 E-mail: tbone@hku.hk (TCB) 


\section{Abstract}

22 Artificial night light has the potential to significantly alter visually-dependent species

23 interactions. However, examples of disruptions of species interactions through changes in light

24 remain rare and how artificial night light may alter predator prey relationships are particularly

25 understudied. In this study, we examined whether artificial night light could impact prey

26 attraction and interception in Nephila pilipes orb weaver spiders, conspicuous predators who

27 make use of yellow color patterns to mimic floral resources and attract prey to their webs. We

28 measured moth prey attraction and interception responses to treatments where we experimentally

29 manipulated the color/contrast of spider individuals in the field (removed yellow markings) and

30 also set up light manipulations. We found that lit webs had lower rates of moth interception than

31 unlit webs. Spider color however had no clear impact on moth interception or attraction rates in

32 lit nor unlit webs. The results show that night light can reduce prey interception for spiders.

33 Additionally, this study highlights how environmental and morphological variation can

34 complicate simple predictions of ecological light pollution's disruption of species interactions. 


\section{Introduction}

42 Artificial night light represents an emerging threat to biodiversity (Hölker et al., 2010). Studies

43 are increasingly demonstrating the widespread impacts of artificial light on species (Longcore \&

44 Rich, 2004), ecological communities (Davies, Bennie \& Gaston, 2012; Gaston et al., 2014) and

45 ecosystem functioning (Macgregor et al., 2017). One important consequence of light pollution

46 and artificial night light is a change in natural light landscapes and seascapes that could alter

47 species communication and interactions (Davies et al., 2013). Within species, visual

48 communication can be disrupted by ecological light pollution with consequences for mating

49 success and population dynamics (Firebaugh \& Haynes, 2016). However, the prospect that

50 artificial light could disrupt visual cues, color perception and species interactions remains an

51 important subject for further empirical study (Delhey \& Peters, 2017).

52 Predator-prey interactions in particular are potentially vulnerable to ecological light pollution.

53 Prey species often rely on specific light conditions for camouflage or crypsis where artificial

54 night light can render such species detectable by predators (Davies et al., 2104; Underwood,

55 Davies \& Queirós, 2017). Light pollution can also impact prey behavior including vigilance

56 effectiveness (Yorzinski et al., 2015) and predator avoidance (Perkin et al., 2011). Similarly,

57 Minnaar et al. (2015) found that bats in lit areas consumed six times more moths than bats in

58 unlit areas, highlighting the importance of night light in attracting moths and dramatically

59 changing the dynamics of a long-evolved predator-prey relationship. Some spiders also appear to

60 take advantage of light attraction of prey species and preferentially choose web building sites 
61 near light sources (Heiling, 1999), potentially explaining why some orb-weaver spiders have

62 successfully established within well-light urban areas (Lowe, Wilder \& Hochuli, 2014).

63 Coloration in spiders is particularly important and recent studies have shown that nocturnal

64 spiders can use body markings as visual lures to attract prey (Tso et al., 2006; Chuang, Yang \&

65 Tso, 2008; Fan, Yang \& Tso, 2009; Zhang et al., 2015). Night vision is a challenge for nocturnal

66 species requiring visual systems that exploit moonlight, zodiacal light, airglow and starlight to

67 distinguish color and detect motion (Warrant, 2004; Cronin et al., 2014). Therefore, nocturnal

68 insects lured to spider coloration might be differentially attracted or deterred under artificial

69 night light.

70 To examine the potential of artificial night light in disrupting a visually driven predator-prey

71 relationship, we manipulated light conditions and spider body coloration in a field experiment of

72 the orb weaver spider, Nephila pilipes. The spider has a distinctive yellow body pattern that is

73 well known as a visual lure for nocturnal prey species (Tso, Lin \& Yang, 2004; Fan, Yang \&

74 Tso, 2009). We predicted that artificial light would decrease the effectiveness of the visual lure

75 and impact prey attraction outcomes for spiders.

77 Materials and methods

78 Study sites and species

79 Nephila pilipes are orb-weaver spiders commonly found in Hong Kong during the wet season

80 (March to November). The species exhibits conspicuous yellow patterns scattered over their 
81 dorsal and ventral cephalothorax, abdomen and legs. N. pilipes hunt diurnally and nocturnally

82 and use these conspicuous color patterns to attract prey (Tso, Lin \& Yang, 2004). Habitats

83 include semi-rural areas in Hong Kong where artificial night light sources from street lamps and

84 housing are common. Six sites were chosen due to their semi-rural characteristics including

85 outlying islands (Lamma Island and Lantau Island), country park forests (Tai Tam, Parker Hill

86 and Pak Tam Chung) and a rural village (So Kwun Wat) (Fig. 1). Sites were close to low-density

87 residential areas where active human disturbance was low relative to nearby urban areas.

89 Experimental design

90 In each site, we searched for adult female spiders in their webs (females are much larger than

91 males in $N$. pilipes and display the visual lures of interest). We chose four spider individuals at

92 each site and each adult was assigned randomly to one of four experimental set ups: (1) spider

93 web was lit by a lamp and yellow spider coloration was not painted away (lit control), (2) yellow

94 spider coloration was painted away by black paint (dark and painted), (3) both light and paint

95 were applied to the spider (lit and painted), and (4) no lamp was present and yellow coloration

96 remained (dark control). All setups within a site were located within 50m of each other. We used

97 magnetic USB mini LED bulbs for the light source (WERTIOO) directed towards the web

98 (approximately one meter from the web) as a light source in lit setups, with paper tape wrapped

99 over the surface to downward adjust the light intensity. These bulbs have a similar emission

100 spectrum as Hong Kong street lamps (i.e. high pressure sodium lamps), characterized by peaks in 
101 wavelength between 450 and $600 \mathrm{~nm}$ (Elvidge \& Keith, 2009). For spider color manipulations,

102 we used black acrylic paint due to its low toxicity and ease of removal (Tamiya Colour Acrylic

103 Paint Mini Black X-1, diluted by thinner of the same brand). We also applied the paint to black

104 body parts of spiders in the yellow coloration "controls" (setups 1 and 4) to exclude possible

105 effects of ink. Spiders were gently removed from their webs and cooled to an inactive state by an

106 ice bath. After treating with paint, they were carefully placed back on their webs for the

107 commencement of the experiment. Spiders generally regained motility about one minute after

108 withdrawal from the ice bath and returned to an un-agitated state several minutes after that.

109 We also recorded body length, the total length of cephalothorax and opisthosoma, of each

110 spider. Web size was measured as the average of web radii in eight cardinal directions, from web

111 hub to the outermost capture spiral following Tso et al. (2006). We measured light intensity once

112 for each treatment by placing a digital light meter (Dr. Meter LX-1330B) one meter (as close to

113 perpendicular to the web as possible given environmental constraints) from the webs at the

114 beginning of the experiment.

115 We examined N. pilipes predation success through single-night videotaping of all

116 experimental spider webs. We recorded from between 7:00 p.m. and 8:00 p.m. to the beginning

117 of sunrise (4:00 a.m. to 5:00 a.m.). We sampled each site once in the fall (August to November)

118 of 2015 and 2016. All setups in each site were recorded on the same night simultaneously.

119 Environmental conditions (moon phase, cloudiness, temperature, etc.) are certain to vary over

120 time and could affect prey attraction and interception rates - however, because all treatments per 
121 site were done on a single night we largely controlled for these factors (these factors were

122 unlikely to vary much within sites). As a trade-off for controlling conditions within sites, the

123 proximity of each treatment within each site allowed for the possibility of moths in one treatment

124 to be affected by another treatment (e.g. lit web attracting moths from an unlit web). We didn't

125 personally observe such effects however and believe that the treatments were largely

126 independent. We used high definition car rearview cameras with infra-red emitters (Theera

127 YRS0889) for the night video recording. N. pilipes mostly builds webs under tree trunks, at a

128 height of one to two meters. Cameras were therefore placed on tripods approximately one meter

129 from each web.

130 We examined prey responses to each treatment by focusing on moths in all video recordings.

131 Moths are a dominant nocturnal prey species of N. pilipes (Fan, Yang \& Tso, 2009). Moths also

132 use a trichromatic visual system, possessing green, blue and ultra-violet light receptors (Briscoe

133 \& Chittka, 2001). Based on a model of a hawkmoth visual system (Johnsen et al., 2006),

134 Chuang, Yang \& Tso (2007) determined that the yellow stripes of N. pilipes were more

135 distinctive under moonlight than black markings. Specifically, the contrast of black body parts of

136 the spiders with vegetation backgrounds was remarkably smaller than those of yellow body parts

137 (Chuang, Yang \& Tso, 2007). Yellow flowers could represent food sources for some moth

138 species such that this coloration pattern might be attractive (Johnsen et al., 2006).

140 Data analysis 
141 We focused on three variables for analysis; attraction (number of moths seen approaching the

142 web), interception (number of moths that physically hit the web, but not necessarily caught in the

143 web) and interception efficiency (number of moths intercepted divided by the number of moths

144 attracted). We used generalized linear mixed models to model the moth attraction and

145 interception data. We fit the models with a negative binomial distribution due to the nature of the

146 count data and the fact that the data were over-dispersed (Zuur et al., 2009). We included site as

147 a random effect and number of hours as an offset term. We modeled web size, color (categorical:

148 painted or not painted), light (categorical: lit or unlit) and spider size as fixed effects and

149 modeled all combinations and first order interactions. We log transformed interception efficiency

150 and used a linear mixed effects model with site as a random effect and web size, spider size,

151 color and light as fixed effects. For the linear mixed effects models, we also examined all first

152 order interactions. All models were run in R using packages glmmADMB and nlme (Pinheiro et

153 al., 2014; Skaug et al., 2014). For each set of generalized linear mixed models and linear mixed

154 effects models, we used model selection and chose the model with the best AICc. For all models

155 where delta $\mathrm{AICc}<4$, we used a model averaging to determine relative variable importance

156 (RVI) using package MuMIn (Barton, 2013).

\section{Results}

159 We recorded 163 hours during the course of the study period. In three cases (two unlit painted

160 treatments and one lit unpainted treatment) the spider left and so we were unable to collect data. 
161 Over the entire recording period we documented 5375 moths attracted and 300 moths intercepted

162 - but only ten moths remained in the web and were consumed by the spider (nine of the ten

163 moths consumed by spiders were done so by unpainted spiders).

164 The best model for attraction included light, color, spider size and the interaction between

165 spider size and color (Table 1; light: estimate \pm se: $-2.40 \pm 0.51, P<0.001$; color: $-13.1 \pm 2.91$,

$166 P<0.001$; size: $-0.18 \pm 0.45, P=0.69$; size:color: $2.65 \pm 0.63, P<0.001)$. In sites with smaller

167 spiders, fewer moths flew near the webs (Fig. 2: for large spiders above $4.5 \mathrm{~cm}, 31.9 \pm 6.1[\mathrm{mean} \pm$

168 standard error] moths attracted/hour and $14.1 \pm 4.7$ for small spiders).

169 For interception, lit webs had lower interception rates (Fig. 3) and the best performing model

170 included only light as a variable (Table 1; light: estimate \pm se: $-2.47 \pm 0.88, P=0.005$ ). Seven

171 models performed equally well (Table 1 ), and of those models light (RVI=1.0) was the most

172 important followed by spider size $(\mathrm{RVI}=0.45)$ and color $(\mathrm{RVI}=0.24)$.

173 For interception efficiency, the best three models were light alone, size alone and light plus

174 size (Table 1; light alone: estimate \pm se: $-0.43 \pm 0.25, P=0.10$; size alone: $-0.33 \pm 0.18, P=0.08$; and

175 light+size: light: $-0.54 \pm 0.26, P=0.05$; size: $-0.37 \pm 0.17, P=0.04)$. Of the five best performing

176 models (Table 1) light was the most important variable $(\mathrm{RVI}=0.61)$ followed by spider size

$177(\mathrm{RVI}=0.47)$ and color $(\mathrm{RVI}=0.19)$. Light tended to diminish interception efficiency (especially

178 for webs with large spiders) and small spiders exhibited a higher efficiency (Fig. 4). For large

179 spiders, those that were unpainted (yellow) and in dark webs had a higher interception efficiency

180 than all other treatment combinations (Fig. 4). 


\section{Discussion}

183 Prey attraction rates were affected by spider size, spider color manipulation, and light conditions

184 but not in a consistent manner (Fig. 2). We did however find a consistent and large effect of light

185 in lowering prey interception $(\sim 1 \mathrm{moth} / \mathrm{hr}$; Fig. 3$)$ comparable to the positive effect of yellow

186 markings documented in previous studies of $N$. pilipes $(\sim 1 \mathrm{moth} / \mathrm{hr}$; Chuang, Yang \& Tso

187 (2007)). In this study, we found no clear consequences of spider color for prey attraction or

188 interception. Yet, spider size and color exhibited an interactive effect for all attraction variables

189 (Table 1) demonstrating the complexity of the relationship between spider morphology and prey

190 attraction outcomes. The lack of clear effects of some variables (e.g. color) on attraction and

191 interception might be a consequence of the relatively low sample sizes of the experiment (six

192 experimental units/ nights). Nevertheless, our results highlight 1) that light can reduce prey

193 interception for spiders and 2) the role of morphological and environmental variation in

194 complicating and potentially obscuring important but difficult-to-detect artificial night light

195 effects on predator-prey interactions.

196 We found that interception rates were lower in lit webs than unlit webs. The lack of an effect

197 of color on interception suggests that the cause for this pattern is unlikely through changes in the

198 effectiveness of the visual lure. Moth flight-to-light responses can be varied and likely determine

199 light's effect on interception rates. Chaotic and undirected flight towards light sources in moths

200 (Frank, 1988) may reduce the effectiveness of webs in prey capture for lit webs. The presence of 
201 light will also change the contrast of the web with its background and could make the web more

202 easily perceived and avoided by moth prey (Craig, 1988; Théry \& Casas, 2009). Alternatively,

203 while some spiders build webs near artificial light sources to take advantage of attracted prey

204 (Heiling, 1999), there might be a tradeoff in web detectability that could offset increased prey

205 availability near light. Further exploration into the costs and benefits of locating webs near

206 artificial night light would be productive in revealing the impacts of ecological light pollution on

207 urban spider populations.

208 For attraction, the light treatment alone did not consistently result in higher attraction rates.

209 While each site had all treatments on the same day to minimize time or site effects on the results,

210 the high variation in attraction may have obscured possible effects of light and morphology. We

211 also only used one type of bulb and higher light intensity sources may have led to clearer results.

212 Light can have strongly contrasting effects on predator-prey interactions depending on the

213 habitat (Russ, Lučeničová \& Klenke, 2017). Environmental conditions across sites and days, and

214 variable light intensity in particular (e.g. different moon phases), may have resulted in complex

215 patterns between the light treatment effects and prey attraction. We did find that, in general,

216 larger spiders had more moths attracted to their webs than smaller spiders (Fig. 2). The higher

217 attraction rate for large spiders could be a consequence of a bigger visual lure capable of

218 attracting more prey than smaller spiders (Hauber, 2002). Alternatively, spiders who select better

219 microhabitats with more prey may grow larger (Brown, 1981) such that the association is driven

220 by greater prey availability increasing spider size, not larger spiders attracting more prey. In any 
221 case, the high heterogeneity of light landscapes across spatial scales in the environment (Swaddle

222 et al., 2015) along with other sources of microhabitat and temporal variation are important

223 considerations for the results of this study as well as ecological light pollution studies broadly.

224 Size and color likely have different effects at variable distances: small spiders may attract

225 fewer prey (or be located in sites with fewer prey) but they also tend to have a higher (but

226 variable) interception efficiency suggesting that their small size might be advantageous in

227 disguising their presence once moths are near the web. For large spiders, the unlit and unpainted

228 (yellow markings intact) treatments had the highest interception efficiency which could be

229 indicative of increased, effectiveness of the lure for large spiders in natural light conditions.

230 However, interception efficiencies across treatments were highly variable across treatments and

231 the mechanisms and effects are difficult to interpret. In addition to the importance of morphology

232 for prey attraction, the visual cues and coloration of $N$. pilipes may also attract their own

233 predators potentially (Fan, Yang \& Tso, 2009; Meyer et al., 2013; Yeh et al., 2015). Artificial

234 night light effects on predator-prey relationships must then take into account multiple

235 morphological variables (e.g. color and size) as well as multiple consequences of those visual

236 cues (e.g. prey attraction and predator attraction).

237 Temporal consequences of artificial night light are worth consideration in this case. For $N$.

238 pilipes, Chuang, Yang \& Tso (2007) found that prey interception was generally higher at night

239 but that diurnal prey interception occurred as well. Light pollution may then shift hunting

240 activity of $N$. pilipes and increase the importance of diurnal prey interception. Circadian 
241 responses to artificial night light, particularly in the context of predator-prey relationships,

242 remain an important avenue of future research (Dominoni, Borniger, \& Nelson 2016).

243 Our results provide insights into the relationship between prey attraction and artificial night

244 light but this study may not be reflective of the entirety of night light impacts on this predator-

245 prey relationship. For example, the short time period covered for each web in this study could

246 miss crucial rare catches of large prey items which may have disproportionate positive impacts

247 on spider fitness (Venner \& Casas, 2005). If light differentially affects or attracts large moths

248 (Wölfling et al., 2016) then the average overall interception rate may be less important than the

249 ability to catch large moths occasionally. Similarly, more important than interception rate, is the

250 rate at which spiders actually consume prey. Though we only observed ten moth consumption

251 events, interestingly, nine of those moths were captured by spiders that were not painted. The

252 effects of artificial night light on predation rates are rarely straightforward and will ultimately be

253 the product of both negative and positive impacts of light on predator and prey behavior (Grenis,

254 Tjossem \& Murphy, 2015).

255 Reduced feeding, mobility and possible increased predation are all potential consequences of

256 artificial night light for moths and these effects may result in trophic cascades within these novel

257 ecosystems (van Langevelde et al., 2017). This study highlights how night light can impact

258 species interactions but also that environmental and morphological variation can obscure simple

259 relationships between predator and prey. As artificial night light continues to dramatically alter

260 the environment (Davies et al., 2013), the conditions under which these predator-prey 
261 relationships have evolved will also change resulting in the possible disruption of important

262 species interactions within ecosystems.

263

264 Conclusion

265 Our experiment demonstrates a clear reduction of prey interception in sites with artificial

266 night light for orb-weaver spiders in Hong Kong. The results also suggest that body size and

267 color might also influence prey interception outcomes for orb-weaver spiders but no clear

268 patterns were detected. Future research into the complex interactions between predator, prey,

269 light and morphology will aid in predictions and understanding of how anthropogenic changes in

270 light are likely to affect ecological communities and ecosystems.

271

272 Acknowledgements

273 We thank Schind Lee and Danny Yuen for their assistance in the field and for their help in

274 managing unpredictable field situations. Jon Bennie and two anonymous reviewers provided

275 useful input that improved the manuscript significantly.

276

277 Literature cited

278 Barton K. 2013. MuMIn: Multi-model inference. R package version 1.9.5

279 Briscoe AD, Chittka L. 2001. The evolution of color vision in insects. Annual Review of

280 Entomology 46:471-510. 
281 Brown KM. 1981. Foraging ecology and niche partitioning in orb-weaving spiders. Oecologia $28250: 380-385$.

283 Chuang CY, Yang EC, Tso IM. 2007. Diurnal and nocturnal prey luring of a colorful predator.

284 Journal of Experimental Biology 210:3830-3837.

285 Chuang CY, Yang EC, Tso IM. 2008. Deceptive color signaling in the night: a nocturnal

286 predator attracts prey with visual lures. Behavioral Ecology 19:237-244.

287 Craig CL. 1988. Insect perception of spider orb webs in three light habitats. Functional Ecology $288 \quad 2: 277-282$.

289 Cronin TW, Johnsen S, Marshall NJ, Warrant EJ. 2014. Visual Ecology. New Jersey: Princeton $290 \quad$ University Press

291 Davies TW, Bennie J, Gaston KJ. 2012. Street lighting changes the composition of invertebrate 292 communities. Biology Letters 8:764-767.

293 Davies TW, Bennie J, Inger R, Ibarra NH, Gaston KJ. 2013. Artificial light pollution: are 294 shifting spectral signatures changing the balance of species interactions? Global Change 295 Biology 19:1417-1423.

296 Davies TW, Duffy JP, Bennie J, Gaston KJ. 2014. The nature, extent, and ecological 297 implications of marine light pollution. Frontiers of Ecology and the Environment 12:347-355.

298 Delhey K, Peters A. 2017. Conservation implications of anthropogenic impacts on visual 299 communication and camouflage. Conservation Biology 31:30-39.

300 Dominoni DM, Borniger JC, Nelson RJ. 2016. Light at night, clocks and health: from humans to 
$301 \quad$ wild organisms. Biology Letters 12:20160015.

302 Elvidge CD, Keith DM. 2009. Spectral Signatures of Nighttime Lights. Resources Center;

303 Available from http://www.asdi.com/resource-center/application-notes/spectral-signatures-of-

304 nighttime-lights

305 Fan C, Yang E, Tso I. 2009. Hunting efficiency and predation risk shapes the color-associated

306 foraging traits of a predator. Behavioral Ecology 20:808-816.

307 Firebaugh A, Haynes KJ. 2016. Experimental tests of light-pollution impacts on nocturnal insect

308 courtship and dispersal. Oecologia 182:1203-1211.

309 Frank KD. 1988. Impact of outdoor lighting on moths: an assessment. Journal of the

$310 \quad$ Lepidopterists' Society 42:63-93.

311 Gaston KJ, Duffy JP, Gaston S, Bennie J, Davies TW. 2014. Human alteration of natural light

312 cycles: causes and ecological consequences. Oecologia 176:917-931.

313 Grenis K, Tjossem B, Murphy SM. 2015. Predation of larval Lepidoptera in habitat fragments

314 varies spatially and temporally but is not affected by light pollution. Journal of Insect

315 Conservation 19:559-566.

316 Hauber ME. 2002. Conspicuous colouration attracts prey to a stationary predator. Ecological

317 Entomology 27:686-691.

318 Heiling AM. 1999. Why do nocturnal orb-web spiders (Araneidae) search for light? Behavioral

319 Ecology and Sociobiology 46:43-49.

320 Hölker F, Wolter C, Perkin EK, Tockne K. 2010. Light pollution as a biodiversity threat. Trends 
in Ecology and Evolution 225:681-682.

322 Johnsen S, Kelber A, Warrant E, Sweeney AM, Widder EA, Lee RL, Hernández-Andrés J. 2006.

323 Crepuscular and nocturnal illumination and its effects on color perception by the nocturnal

324 hawkmoth Deilephila elpenor. Journal of Experimental Biology 209:789-800.

325 Longcore T, Rich C. 2004. Ecological light pollution. Frontiers in Ecology and the Environment $326 \quad 2004: 191-198$.

327 Lowe EC, Wilder SM, Hochuli DF. 2014. Urbanisation at multiple scales is associated with 328 larger size and higher fecundity of an orb-weaving spider. PLoS One 9:e105480.

329 Macgregor CJ, Evans DM, Fox R, Pocock MJ. 2017. The dark side of street lighting: impacts on 330 moths and evidence for the disruption of nocturnal pollen transport. Global Change Biology $331 \quad 23: 697-707$.

332 Meyer LA, Sullivan SMP. 2013. Bright lights, big city: influences of ecological light pollution 333 on reciprocal stream-riparian invertebrate fluxes. Ecological Applications 23:1322-1330.

334 Minnaar C, Boyles JG, Minnaar IA, Sole CL, McKechnie AE. 2015. Stacking the odds: light 335 pollution may shift the balance in an ancient predator-prey arms race. Journal of Applied 336 Ecology 52:522-531.

337 Perkin EK, Hölker F, Richardson JS, Sadler JP, Wolter C, Tockner K. 2011. The influence of 338 artificial light on stream and riparian ecosystems: questions, challenges, and perspectives. 339 Ecosphere 2:1-16.

340 Pinheiro J, Bates D, DebRoy S, Sarkar D. 2014. nlme: linear and nonlinear mixed effects 
341 models. R package version 3.1-117

342 Russ A, Lučeničová T, Klenke R. 2017. Altered breeding biology of the European blackbird 343 under artificial light at night. Journal of Avian Biology doi: 0.1111/jav.01210

344 Skaug H, Fournier D, Nielsen A, Magnusson A, Bolker B. 2014. glmmADMB: generalized

345 linear mixed models using AD Model Builder. R package version 0.8.0

346 Swaddle JP, Francis CD, Barber JR, Cooper CB, Kyba CC, Dominoni DM, Shannon G,

347 Aschehoug E, Goodwin SE, Kawahara AK, Luther D, Spoelstra K, Voss M, Longcore T.

348 2015. A framework to assess evolutionary responses to anthropogenic light and sound. Trends

349 in Ecology and Evolution 30:550-560.

350 Théry M, Casas J. 2009. The multiple disguises of spiders: web colour and decorations, body

351 colour and movement. Philosophical Transactions of the Royal Society B Biological Sciences

$352 \quad 364: 471-480$.

353 Tso I, Lin C, Yang E. 2004. Colourful orb-weaving spiders, Nephila pilipes, through a bee's

354 eyes. Journal of Experimental Biology 207:2631-2637.

355 Tso I, Liao C, Huang R, Yang E. 2006. Function of being colorful in web spiders: attracting prey

356 or camouflaging oneself? Behavioral Ecology 17:606-613.

357 Tuanmu MN, Jetz W. 2014. A global 1-km consensus land-cover product for biodiversity and

358 ecosystem modelling. Global Ecology and Biogeography, 23:1031-1045.

359 Underwood CN, TW Davies, Queirós AM. 2017. Artificial light at night alters trophic

360 interactions of intertidal invertebrates. Journal of Animal Ecology 86:781-789. 
361 van Langevelde F, van Grunsven RH, Veenendaal EM, Fijen TP. 2017. Artificial night lighting

362 inhibits feeding in moths. Biology Letters 13: doi: 10.1098/rsbl.2016.0874.

363 Venner S, Casas J. 2005. Spider webs designed for rare but life-saving catches. Proceedings of

364 the Royal Society of London B Biological Sciences 272:1587-1592.

365 Warrant E. 2004. Vision in the dimmest habitats on Earth. Journal of Comparative Physiology A

$366 \quad 190: 765-789$.

367 Wölfling M, Becker MC, Uhl B, Traub A, Fiedler K. 2016. How differences in the settling

368 behaviour of moths (Lepidoptera) may contribute to sampling bias when using automated

369 light traps. European Journal of Entomology 113:5027-506.

370 Yeh CW, Blamires SJ, Liao CP, Tso IM. 2015. Top down and bottom up selection drives

371 1variations in frequency and form of a visual signal. Scientific Reports 5:9543.

372 Yorzinski JL, Chisholm S, Byerley SD, Coy JR, Aziz A, Wolf JA, Gnerlich AC. 2015. Artificial

373 light pollution increases nocturnal vigilance in peahens. PeerJ 3:e1174.

374 Zhang S, Chen H, Chen K, Huang J, Chang C, Piorkowski D, Liao C, Tso I. 2015. A nocturnal

375 cursorial predator attracts flying prey with a visual lure. Animal Behaviour 102:119-125.

376 Zuur AF, Ieno EN, Walker NJ, Saveliev AA, Smith GM. 2009. Zero-truncated and zero-inflated

377 models for count data. In: Mixed effects models and extensions in ecology with R. New York:

378 Springer; pp. 261-293

379

380 


\section{Table $\mathbf{1}$ (on next page)}

Model results for attraction, interception and interception efficiency.

We used generalized linear mixed models (GLMM) for attraction and interception and linear mixed effects models (LMM) for interception efficiency. Fixed effects include color, light, spider size (Size), and web size (Web). 


\begin{tabular}{|c|c|c|c|c|}
\hline Models & \multicolumn{2}{|c|}{ Log-likelihood $\mathrm{AIC}_{\mathrm{c}}$} & $\begin{array}{l}\mathrm{AIC}_{\mathrm{c}} \\
\text { Delta }\end{array}$ & $\begin{array}{l}\text { Akaike } \\
\text { Weight }\end{array}$ \\
\hline \multicolumn{5}{|l|}{ Moth attraction (GLMM) } \\
\hline Color, Light, Size, Color:Size & -145.14 & 312.9 & 0.00 & 0.61 \\
\hline \multicolumn{5}{|l|}{ Moth interception (GLMM) } \\
\hline Light & -95.47 & 201.4 & 0.00 & 0.31 \\
\hline Light, Size & -94.29 & 202.6 & 1.13 & 0.18 \\
\hline Color, Light, Size, Color:Size & -90.65 & 203.9 & 2.48 & 0.09 \\
\hline Light, Web & -95.18 & 204.4 & 2.92 & 0.07 \\
\hline Color, Light & -95.39 & 204.8 & 3.35 & 0.06 \\
\hline Light, Size, Web & -93.64 & 205.3 & 3.84 & 0.05 \\
\hline Color, Light, Size & -93.665 & 205.3 & 3.89 & 0.04 \\
\hline \multicolumn{5}{|l|}{ Interception efficiency (LMM) } \\
\hline Light & -20.83 & 52.2 & 0.00 & 0.35 \\
\hline Size & -21.56 & 53.6 & 1.47 & 0.17 \\
\hline Light, Size & -19.90 & 53.8 & 1.65 & 0.15 \\
\hline Color & -22.17 & 54.8 & 2.68 & 0.09 \\
\hline Color, Size, Color:Size & -18.70 & 55.4 & 3.24 & 0.07 \\
\hline
\end{tabular}




\section{Figure 1 (on next page)}

Map of the study sites across Hong Kong

Percent urban area is based on the one km resolution land cover dataset of Tuanmu \& Jetz (2014). 


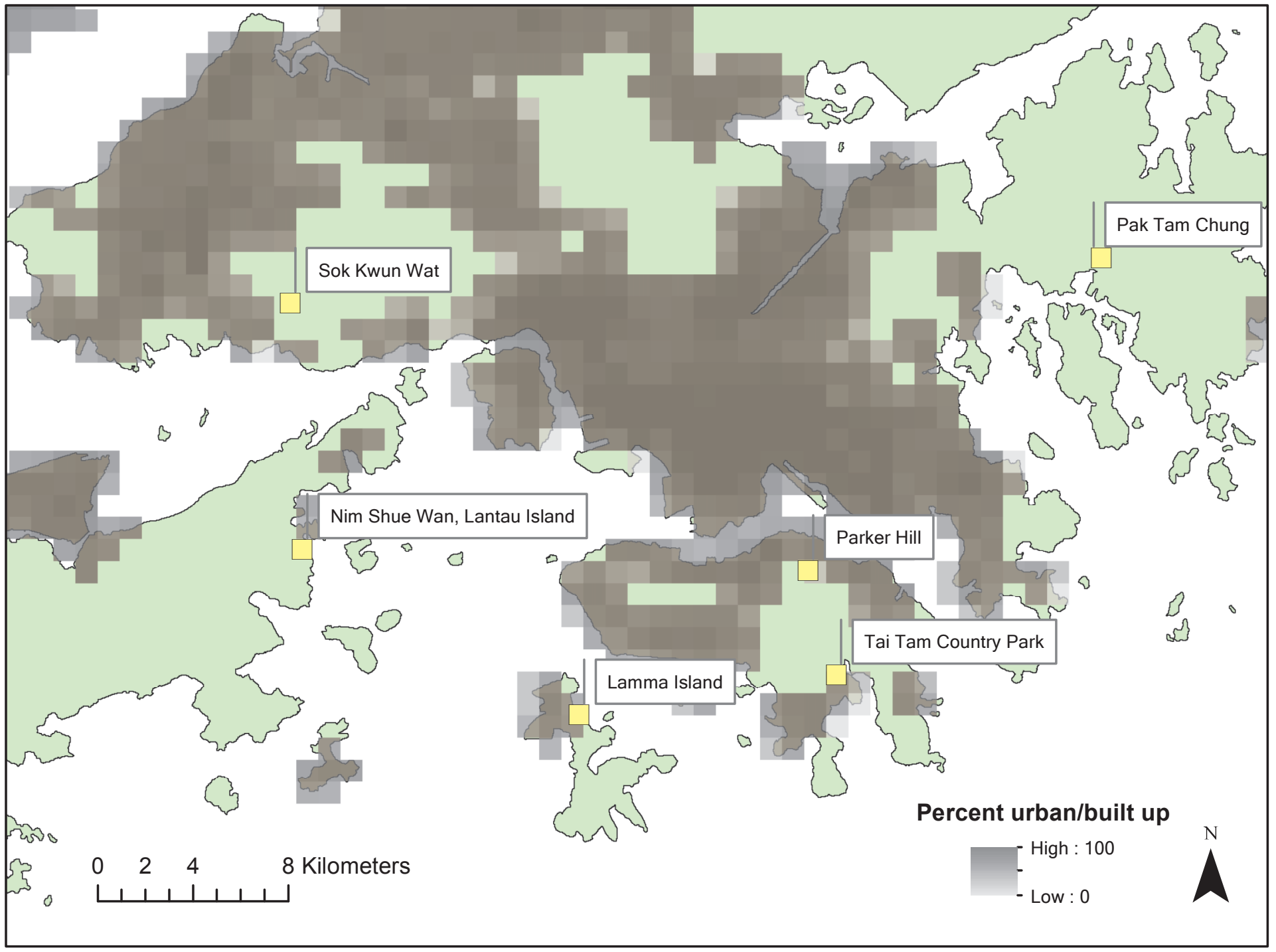




\section{Figure 2 (on next page)}

Prey attraction rates (number of moths/ hour) across color and light treatments.

Error bars indicate mean \pm standard error. Spider size was broken down into categorical variable for visualization, where spiders above $4.5 \mathrm{~cm}$ were identified as large $(A)$ and were otherwise identified as small (B). Data points are scaled to spider size (in cm). 


\section{Figure 3 (on next page)}

Moth interception rate as a function of spider color and light.

Error bars indicate mean \pm standard error. 


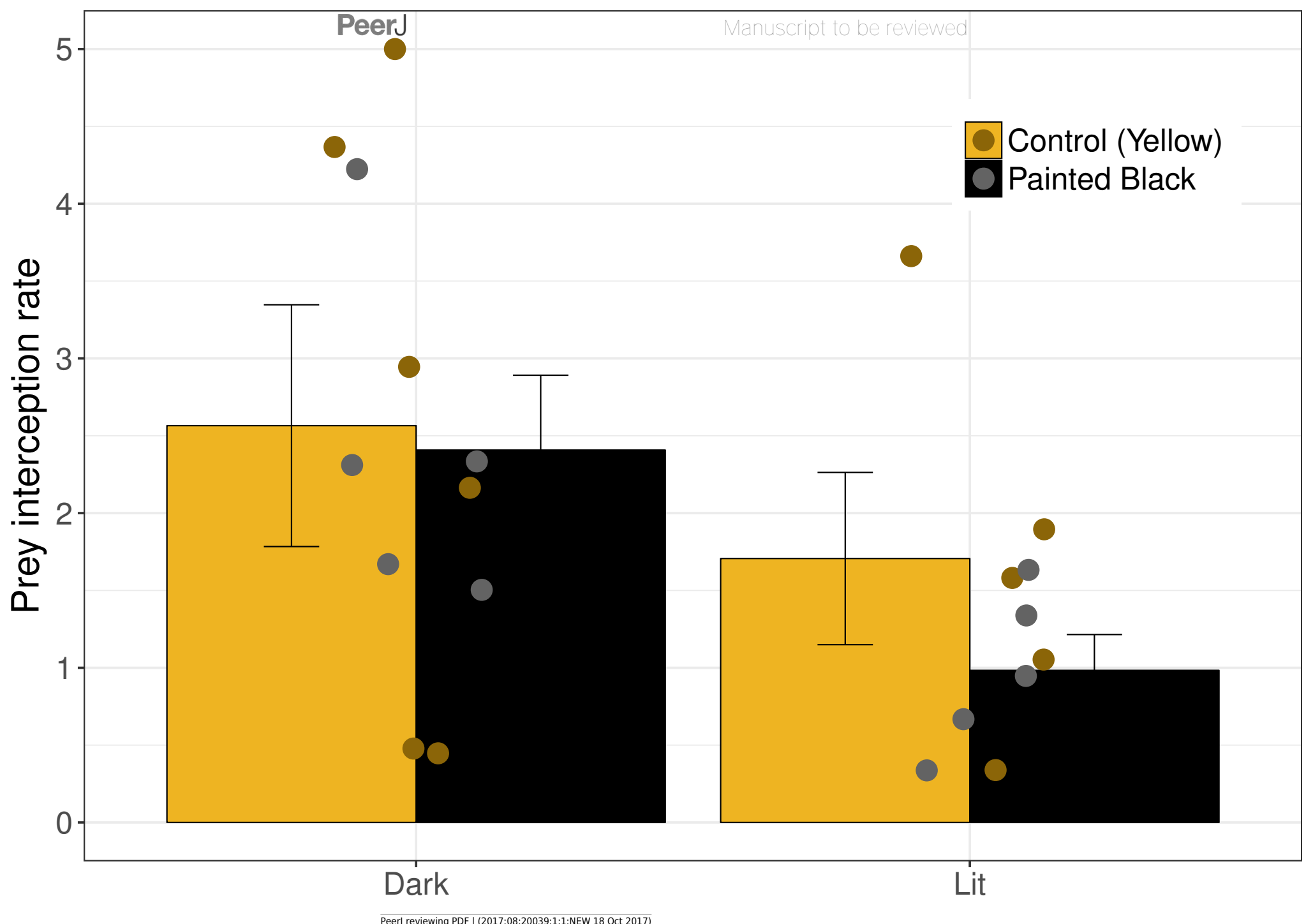




\section{Figure 4 (on next page)}

Interception efficiency across color and light treatments.

Error bars indicate mean \pm standard error. Spider size was broken down into categorical variable for visualization, where spiders above $4.5 \mathrm{~cm}$ were identified as large $(A)$ and were otherwise identified as small (B). Data points are scaled to spider size (in cm). 


\section{(A) Pârge spiders}

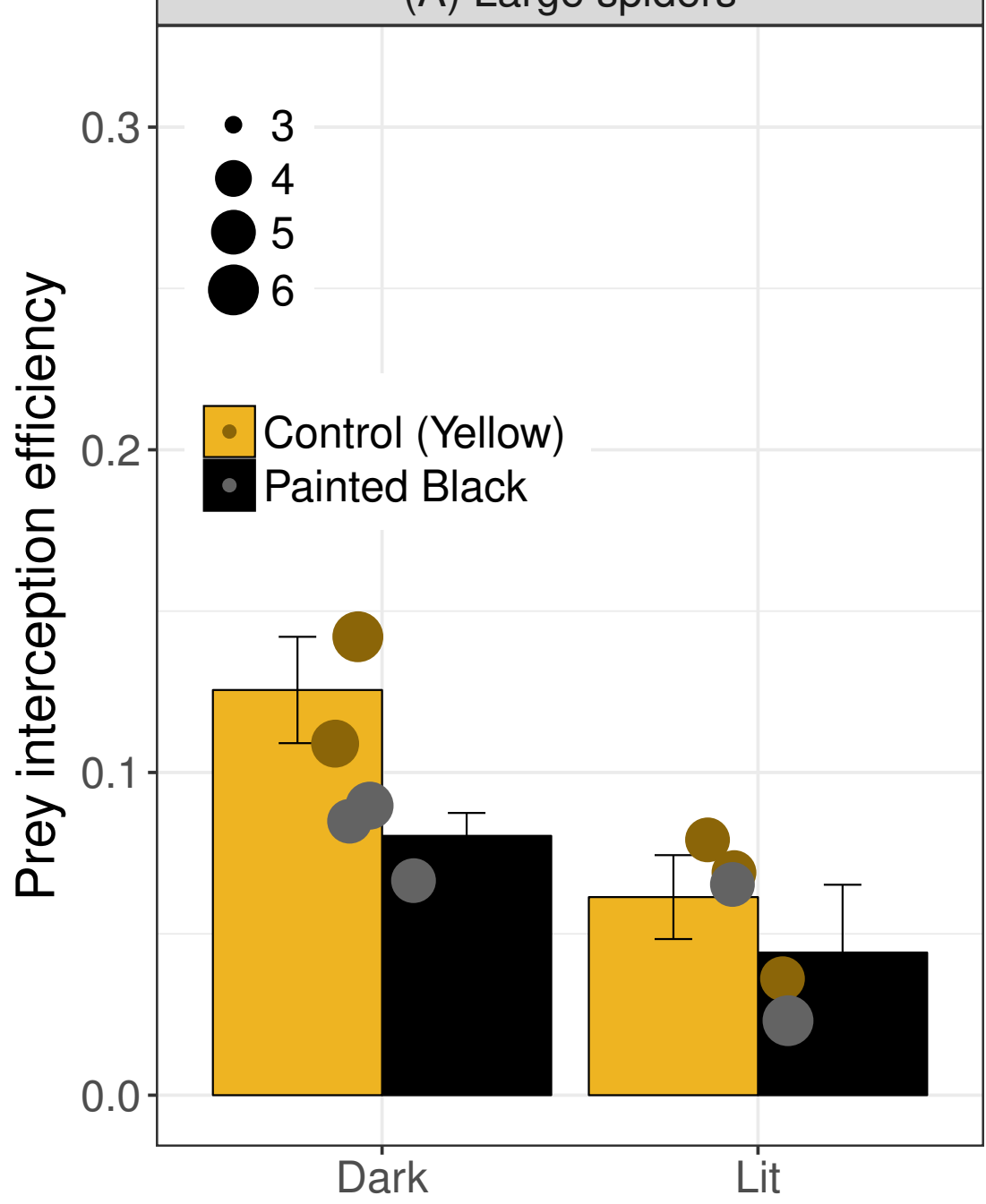

Manuscript to be $(\mathrm{B})$ 'S'mall spiders

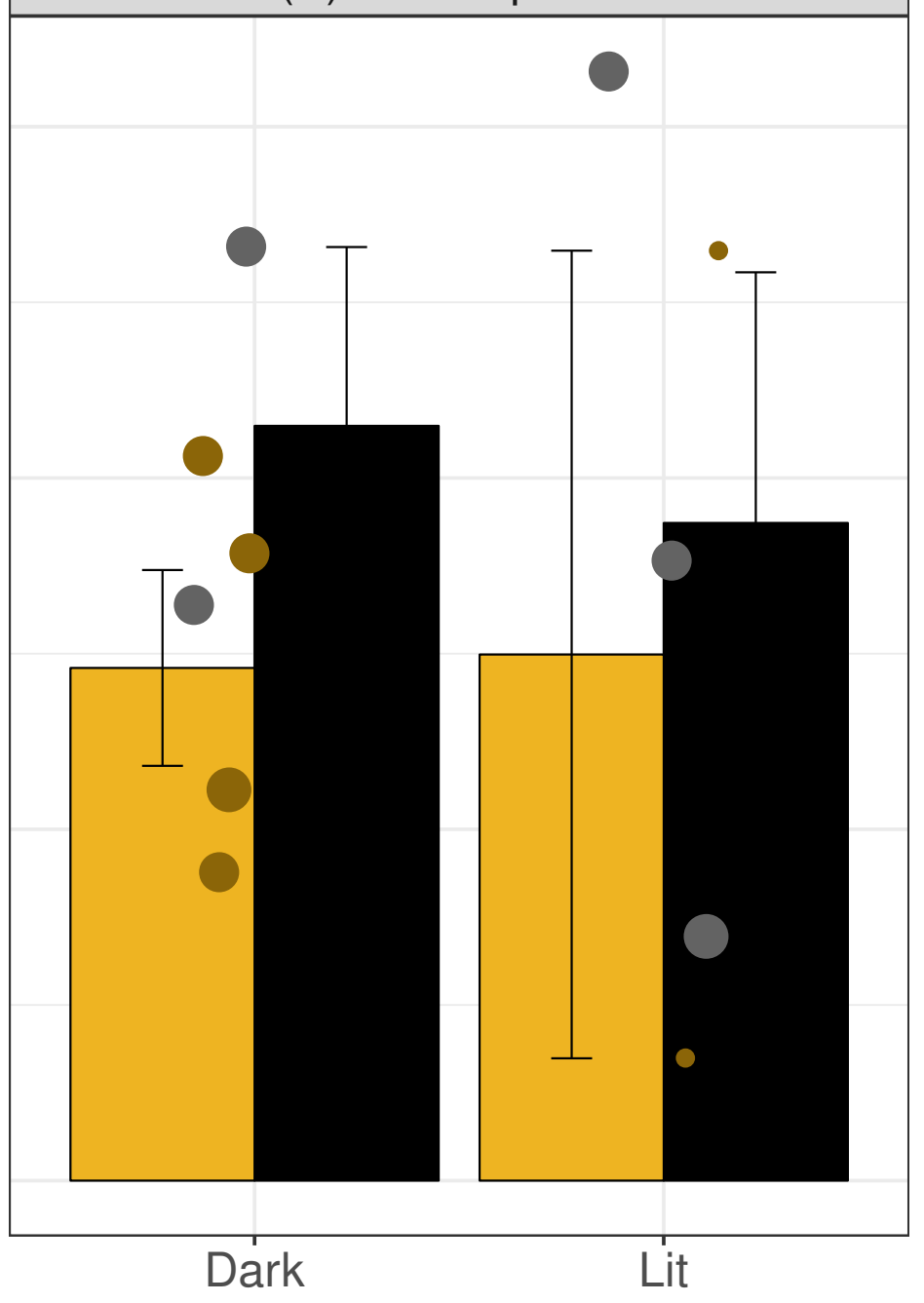

